\title{
How many people need palliative care? A study developing and comparing methods for population-based estimates
}

\author{
Fliss EM Murtagh', Claudia Bausewein², Julia Verne ${ }^{3}$, \\ E Iris Groeneveld', Yvonne E Kaloki' and Irene J Higginson'
}

\begin{abstract}
Background: Understanding the need for palliative care is essential in planning services.

Aim: To refine existing methods of estimating population-based need for palliative care and to compare these methods to better inform their use.

Design: (I) Refinement of existing population-based methods, based on the views of an expert panel, and (2) application/comparison of existing and refined approaches in an example dataset. Existing methods vary in approach and in data sources. (a) Higginson used cause of death/symptom prevalence, and using pain prevalence, estimates that $60.28 \%$ ( $95 \%$ confidence interval $=60.20 \%-60.36 \%$ ) of all deaths need palliative care, (b) Rosenwax used the International Statistical Classification of Diseases and Related Health Problems-10th Revision (ICD-I0) causes of death/hospital-use data, and estimates that $37.01 \%$ ( $95 \%$ confidence interval $=36.94 \%-37.07 \%$ ) to $96.61 \%$ $(95 \%$ confidence interval $=96.58 \%-96.64 \%)$ of deaths need palliative care, and (c) Gómez-Batiste used percentage of deaths plus chronic disease data, and estimates that $75 \%$ of deaths need palliative care.

Setting/participants: All deaths in England, January 2006-December 2008, using linked mortality and hospital episode data.

Results: Expert panel review identified changing practice (e.g. extension of palliative care to more non-cancer conditions), changing patterns of hospital/home care and multiple, rather than single, causes of death as important. We therefore refined methods (using updated ICD-I 0 causes of death, underlying/contributory causes, and hospital use) to estimate a minimum of $63.03 \%(95 \%$ confidence interval $=62.95 \%-63.11 \%)$ of all deaths needing palliative care, with lower and upper mid-range estimates between $69.10 \%(95 \%$ confidence interval $=69.02 \%-69.17 \%)$ and $81.87 \%(95 \%$ confidence interval $=81.81 \%-81.93 \%)$.

Conclusions: Death registration data using both underlying and contributory causes can give reliable estimates of the populationbased need for palliative care, without needing symptom or hospital activity data. In high-income countries, $69 \%-82 \%$ of those who die need palliative care.
\end{abstract}

\section{Keywords}

Palliative care, needs assessment, public health, health services needs and demand, delivery of health care, end-of-life care, terminal care

\section{Background}

Needs and needs assessment have different meanings depending on who uses these terms and for what purpose. ${ }^{1}$ Need for health care has been defined as 'the population's ability to benefit from healthcare', ${ }^{2}$ and this understanding of need is useful in considering national or regional needs assessment for palliative care. Need has been further categorised by Bradshaw, ${ }^{3}$ according to the perspective and action adopted, as being either 'felt' need (individual perceptions of need), 'expressed' need (individual perceptions of need that result in demand), 'normative' need (professionals' perceptions of need) or 'comparative' need (need compared across different groups or providers). In order to consider the need for palliative care in a national

\footnotetext{
'King's College London, Cicely Saunders Institute, London, UK ${ }^{2}$ Interdisciplinary Centre for Palliative Medicine, Munich University, Munich, Germany

${ }^{3}$ South West Public Health Observatory, Bristol, UK
}

\section{Corresponding author:}

Fliss EM Murtagh, Cicely Saunders Institute, Bessemer Rd, London SE5 9PJ, UK.

Email: fliss.murtagh@kcl.ac.uk 
population, we adopt the perspective of 'ability to benefit' from palliative care, from a normative (professionally defined) perspective.

Services in all health sectors provide day-to-day care to patients with advanced disease. Designed to alleviate symptoms and concerns, but not expected to cure the disease, this kind of care, provided by primary care professionals or by specialists treating patients with life-threatening diseases, is defined as 'general palliative care'. ${ }^{4-6}$ In contrast, specialist palliative care is provided by specialised services for patients with complex problems not adequately covered by other treatment options ${ }^{4}$ and is delivered by a multiprofessional team with recognised specialist training. ${ }^{6}$ Both general and specialist palliative care are delivered in many different ways across settings, from home-based palliative care delivered by primary and community care teams to diverse specialist palliative care services for those with highly complex needs. For this reason, it is difficult for estimations of the need for palliative care to be extrapolated from one or more services to a regional or national level. Population-based estimates of the need for palliative care are therefore invaluable for those commissioning or planning services, but are infrequently used, with poorly developed methods.

For a population, the starting point for estimating need for palliative care is the number of deaths. ${ }^{1}$ Three different approaches have been developed in the United Kingdom, ${ }^{1}$ Australia ${ }^{7}$ and Spain. ${ }^{8}$ These use different combinations of mortality statistics, combined with symptom prevalence, disease prevalence, or hospital service use. But the various methods have never been compared and contrasted.

In order to develop robust estimates of palliative care need, and ensure appropriate service development, it is important to understand the differences between these methods, including which method is best applied and when. The approaches vary in their complexity and sometimes rely on primary data that are not always available. It is important to understand whether the more complex approaches add value to the assessment, the implications of using these different methods and to develop more standardised and comparable approaches. In this study, we therefore aim to refine existing methods of estimating population-based need for palliative care and to compare the results from these methods to better inform their use.

\section{Methods}

\section{Design}

This study had two components: (1) refinement of existing population-based methods of assessing population-based need for palliative care, based on the views on an expert panel, and (2) application and comparison of both existing and refined approaches in an example dataset, using linked Office for National Statistics (ONS) mortality data and
Hospital Episode Statistics (HES) data. Three different approaches to assessing population need, developed in the United Kingdom, ${ }^{1}$ Australia ${ }^{7}$ and Spain were reviewed. ${ }^{8}$

\section{Setting}

We used national population data from England as an example, to standardise the setting and data for comparison. In England, approximately 470,000 people die each year. ${ }^{9}$

\section{Data}

Data on the numbers and causes of death were derived from death registrations, collected for England by the ONS. ${ }^{9}$ This provides data on cause of death for every death in England, as well as other demographic details. From the death certificate, the causes of death are classified using the International Statistical Classification of Diseases and Related Health Problems-10th Revision $(I C D-10) .{ }^{10}$ Causes of death are classified as (1) the underlying cause of death, defined as the disease or injury that initiated the train of events directly linked to death or the circumstances of the accident or violence that produced the fatal injury, and (2) contributory cause of death, defined as part of the causal sequence of events leading to death or contributing to the death but not part of the causal sequence. ${ }^{11}$ Underlying and contributory causes capture those conditions recorded by the certifying clinician as leading to or influencing the death. We used data on all deaths in England, over the 3-year period from 2006 to 2008 (the most recent linked data available). Data on hospital admissions for the same period were derived from the HES, a national statistical data warehouse for England provided by all National Health Service (NHS) hospitals and for NHS hospital patients treated elsewhere; we used these two linked datasets (death registrations and HES) as combined in the linked ONS/HES mortality dataset. ${ }^{12}$ The linked data were used with the permission of the Health and Social Care Information Centre (HSCIC). The HSCIC retains copyright of this information, with all rights reserved.

\section{Analysis}

Existing methods for assessing population-based need for palliative care were reviewed by an expert panel of clinicians, including palliative care, primary care, and public health clinicians, to identify areas for potential refinement and to consider whether they reflected current palliative care practice. We tested potential refinements to understand what was feasible and useful, with further review from the expert panel. Then, we applied the different methods to the number of deaths in England over the 3-year period of 2006-2008, using the ONS death 
registration data, to compare and contrast the different approaches. Using files containing the linked ONS mortality data and HES, ${ }^{12}$ we investigated death registrations and related patterns of hospital admissions across palliative care-relevant conditions to further refine and develop a new approach to population-based estimation of palliative care need. Table 1 compares and contrasts the different approaches to assessing population need for palliative care and also includes our subsequently developed refined method for comparison.

Using routine mortality statistics for a population in order to assess palliative care needs was an approach adopted by Higginson ${ }^{1}$ in one of the earliest populationbased needs assessments for palliative care. This used the numbers of deaths from cancer and six selected non-cancer disease groups multiplied by symptom prevalence in those groups for the key symptoms requiring palliative care, to derive estimates of need.

In Western Australia, Rosenwax et al. ${ }^{7}$ used literature review and focus groups to further develop the method of using routine mortality statistics to estimate the need for cancer and non-cancer palliative care in a population, using all deaths from any of 10 specific disease groups. Rosenwax et al. ${ }^{7}$ proposed three estimates: a minimal estimate based on the number of deaths from these 10 specific conditions, recognised through expert consensus as likely to need palliative care; a mid-range estimate that included all deaths hospitalised with the same condition as certified on the death certificate sometime in the year before death and a maximal estimate that included all deaths apart from those from poisoning, injury, and maternal, neonatal or perinatal deaths.

In Catalonia, Gómez-Batiste et al. ${ }^{8}$ estimated that $75 \%$ of all deaths were from chronic progressive diseases and proposed also considering prevalence of chronic diseases, dementia and nursing home patients to further refine this.

There are limitations to all three of these approaches. First, palliative care practice is evolving rapidly to include other non-cancer conditions (beyond those considered either by Higginson or subsequently by Rosenwax et al.), such as stroke and dementia. GómezBatiste incorporates these developments in palliative care practice and refines using data on the prevalence of those living with advanced chronic disease, older people with pluripathology, dementia and care home residence, ${ }^{8}$ but epidemiological data of the last type are not always available, and it is not clear from the description by Gómez-Batiste how to incorporate them into an overall estimate when available. Second, death certification is not always accurate in ascertaining actual cause of death. This is particularly true for some of the conditions to which palliative care has more recently extended. ${ }^{13,14}$ Third, even with specific disease groups, not all those who die from the condition will have recognisable palliative care needs prior to death. Higginson partly addresses this by considering prevalence of symptoms, but there are other dimensions too; among some with chronic conditions, their death may be unexpected and unpredictable and may therefore occur before palliative care needs develop. It has been estimated that about $25 \%$ of all deaths in England are unexpected deaths from acute causes, ${ }^{7-9}$ and this varies across causes. Many patients with chronic disease may die unexpectedly, and it has been suggested that this could increase the proportion of unexpected deaths to $40 \% .^{10}$

In our review of these existing methods with the expert group, we therefore hypothesised that (1) refined and updated selection of $I C D-10$ codes, (2) more detailed analysis of the role of underlying and contributory causes of death and (3) considerations of patterns of hospitalisation prior to death could better represent current practice, capture some of these newly emerging conditions and increase the range of population-based methods to estimate palliative care needs.

\section{Results}

\section{Refinement of existing methods}

Examination of the range of $I C D-10$ codes selected for the minimal estimate by Rosenwax et al. ${ }^{7}$ revealed significant under- or over-counting for a number of important chronic conditions for which palliative care is required, partly reflecting changing diagnostic and practice patterns over recent years. We therefore reviewed and refined the Rosenwax categorisation with our expert panel, using a more detailed breakdown of ICD-10 codes for inclusion and exclusion (see Table 1). This also drew on earlier work undertaken for the UK National End of Life Intelligence Network, which focused on the different disease areas such as neoplasms, neurodegenerative diseases, ${ }^{15}$ renal disease, ${ }^{16}$ Alzheimer's disease, dementia and senility, ${ }^{14}$ and other chronic conditions. ${ }^{17,18}$.

In our more detailed breakdown of $I C D-10$ codes, we made the following changes to the $I C D-10$ categorisations from the Rosenwax method: neoplasm codes were refined to exclude benign neoplasms. Heart failure was extended to include chronic heart disease, including hypertensive and ischaemic heart disease as well as cerebrovascular disease (since a separate category for stroke was not adopted). Renal failure was refined to include both acute and chronic renal failure, renal ischaemia and infarction, renal malignancy and hypertensive renal disease. Liver disease was extended to include all chronic liver diseases (beyond alcoholic liver disease and chronic or unspecified hepatic failure). The chronic obstructive pulmonary disease category of Rosenwax was extended to include other chronic respiratory diseases and neurodegenerative 
Table I. Comparison of population-based methods to estimate palliative care need.

\begin{tabular}{|c|c|c|c|}
\hline Author & Method & Data required & $\begin{array}{l}\text { Patient groups included (ICD-I } 0 \text { codes } \\
\text { provided where used) }\end{array}$ \\
\hline \multirow[t]{3}{*}{ Higginson' } & $\begin{array}{l}\text { Uses number of people with selected causes } \\
\text { of death (grouped as cancer and six non- } \\
\text { cancer areas), multiplied by standard symptom } \\
\text { prevalence (separately for cancer and non- } \\
\text { cancer patients, prevalence estimated from } \\
\text { systematic reviews). }\end{array}$ & $\begin{array}{l}\text { Disease-specific } \\
\text { mortality (plus } \\
\text { systematic reviews of } \\
\text { symptom prevalence } \\
\text { in relevant diseases) }\end{array}$ & All cancer deaths \\
\hline & & & $\begin{array}{l}\text { Non-cancer deaths from disease of } \\
\text { circulatory system, respiratory system, } \\
\text { chronic liver and cirrhosis, nervous system } \\
\text { and sense organs (including Parkinson's } \\
\text { disease, multiple sclerosis and meningitis), } \\
\text { senile and pre-senile conditions, and } \\
\text { endocrine, nutritional, metabolic and } \\
\text { immunity disease }\end{array}$ \\
\hline & $\begin{array}{l}\text { It follows an approach of UK Department } \\
\text { of Health for epidemiologically based } \\
\text { needs assessments. Method also considers } \\
\text { effectiveness of services and existing models of } \\
\text { care to triangulate need. }\end{array}$ & & \\
\hline \multirow[t]{2}{*}{$\begin{array}{l}\text { Rosenwax } \\
\text { et al. }{ }^{7}\end{array}$} & $\begin{array}{l}\text { Uses number of people with } 10 \text { selected causes } \\
\text { of death. }\end{array}$ & $\begin{array}{l}\text { Disease-specific } \\
\text { mortality }\end{array}$ & $\begin{array}{l}\text { All cancer deaths (C00-D48) - both } \\
\text { malignant and benign neoplasms included }\end{array}$ \\
\hline & & & 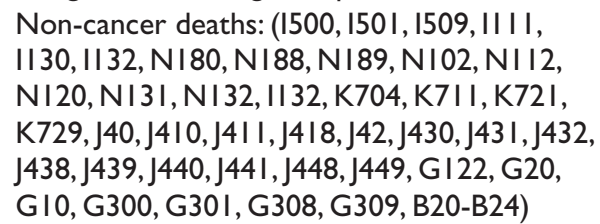 \\
\hline
\end{tabular}

Provides three estimates:

Linked hospital

admissions data

A minimal estimate based on the number of deaths from 10 specific conditions.

A mid-range estimate that included all deaths hospitalised with the same condition as certified on the death certificate sometime in the year before death.

A maximal estimate that included all deaths apart from poisoning, injury, and maternal, neonatal or perinatal deaths.

Gómez- Uses number of people with all causes of death Batiste et and takes $75 \%$ of these as estimate of need for al. ${ }^{8}$
Also considers the following:

I. Prevalence of patients living with advanced chronic disease, with limited life prognosis (to be multiplied by the population size).

2. Prevalence of pluripathology and dependency in elderly people ( $\geq 65$ years).

3. Prevalence of dementia ( $\geq 65$ years).

4. Prevalence of elderly people living in nursing homes or homes for the elderly ( $\geq 65$ years).
Total mortality, all causes

Prevalence of disease, dependency, multiple pathology, symptom and housing data
All cause deaths

Patients living with advanced chronic disease and limited life prognosis

Elderly with pluripathology and dependency 
Table I. (Continued)

\begin{tabular}{|c|c|c|c|}
\hline Author & Method & Data required & $\begin{array}{l}\text { Patient groups included (ICD-IO codes } \\
\text { provided where used) }\end{array}$ \\
\hline & & & Elderly with dementia \\
\hline & & & $\begin{array}{l}\text { Elderly living in nursing homes or homes for } \\
\text { the elderly }\end{array}$ \\
\hline \multirow[t]{4}{*}{$\begin{array}{l}\text { Murtagh } \\
\text { (methods } \\
\text { developed } \\
\text { in this } \\
\text { article) }\end{array}$} & $\begin{array}{l}\text { Uses number of people with selected } \\
\text { underlying cause of death (updated to current } \\
\text { practice) plus contributing cause of death for } \\
\text { selected groups of conditions, as a way to } \\
\text { estimate co-morbidities. }\end{array}$ & $\begin{array}{l}\text { Disease-specific } \\
\text { mortality }\end{array}$ & $\begin{array}{l}\text { All cancer deaths (C00-C97) - malignant } \\
\text { neoplasms only included }\end{array}$ \\
\hline & & $\begin{array}{l}\text { Linked hospital } \\
\text { admissions data }\end{array}$ & \\
\hline & & & $\begin{array}{l}\text { Non-cancer (ICD-I 0: I00-I52, I60-I69, NI7, } \\
\text { NI8, N28, C64, II 2, II 3, K70-K77, J06-JI8, } \\
\text { J20-J22, J40-J47 and J96, GI0, G20, G35, } \\
\text { GI22, G903, G23 I, F0I, F03, G30, R54, } \\
\text { B20-B24) }\end{array}$ \\
\hline & $\begin{array}{l}\text { Provides four estimates: } \\
\text { A minimal estimate based on the number of } \\
\text { deaths from specific conditions. } \\
\text { A lower mid-range estimate that extends } \\
\text { the low estimate of Rosenwax by also } \\
\text { including cases admitted to hospital in the } \\
\text { year before death with the same condition } \\
\text { as documented as 'cause of death', in } \\
\text { addition to deaths for which Alzheimer's, } \\
\text { dementia, senility or chronic renal failure } \\
\text { is recorded as a contributory cause (to } \\
\text { further identify these specifically under- } \\
\text { reported diseases). } \\
\text { An upper mid-range estimate includes all } \\
\text { deaths with any mention on the death } \\
\text { certificate (underlying or contributory) of } \\
\text { the disease categories used for the minimum } \\
\text { estimate. } \\
\text { Maximal estimate as per Rosenwax et al. }{ }^{7}\end{array}$ & & \\
\hline
\end{tabular}

ICD-I0: International Statistical Classification of Diseases and Related Health Problems-I0th Revision.

disease was expanded beyond motor neurone disease, Parkinson's disease and Huntington's disease to also include multiple sclerosis, multi-system degenerative conditions and progressive supranuclear palsy. The category of Alzheimer's used by Rosenwax was expanded from early and late onset Alzheimer's, plus other and unspecified Alzheimer's disease, to include also vascular dementia, unspecified dementia, all types of Alzheimer's disease and senility. The HIV/AIDS codes were unchanged (Table 2).

\section{Application and comparison of approaches}

Table 3 reports the numbers of deaths in England for the 3 -year period of 2006-2008, comparing the original
Rosenwax ICD-10 categorisation and our refined approach outlined above. While the exclusion of benign neoplasms has (as expected) little impact, the inclusion of chronic heart disease and stroke markedly expands the number of deaths in this category. Both the liver and respiratory disease categories increase modestly. A major increase is seen in the dementia group, with the inclusion of the non-specific $I C D-10$ categories for dementia and senility increasing the numbers in this group between fourfold and fivefold.

The approach of Rosenwax (all deaths hospitalised with the same condition as certified on the death certificate sometime in the year before death) for the mid-range estimate may not be precise. Differences by condition in the proportion hospitalised, or consistent under-use of 
Table 2. Comparison of ICD-IO codes selected by Rosenwax and by our refined method.

\begin{tabular}{|c|c|}
\hline Cause of death & $I C D-10$ codes \\
\hline \multicolumn{2}{|l|}{ Rosenwax et al. ${ }^{7}$} \\
\hline Neoplasm & C00-D48 \\
\hline Heart failure & $1500,1501,1509,11111,1130,1132$ \\
\hline Renal failure & NI80, NI88, NI89, NI02, NII2, NI20, NI3I, NI32, II 32 \\
\hline Liver failure & $\mathrm{K} 704, \mathrm{~K} 7 \mathrm{II}, \mathrm{K} 72 \mathrm{I}, \mathrm{K} 729$ \\
\hline Chronic obstructive pulmonary disease & $\begin{array}{l}\mathrm{J} 40, \mathrm{~J} 4 \mathrm{I} \text { 0, J4 II I, J4 I 8, J42, J430, J43 I, J432, J438, J439, J440, } \\
\mathrm{J} 44 \mathrm{I}, \mathrm{J} 448, \mathrm{~J} 449\end{array}$ \\
\hline \multicolumn{2}{|l|}{ Neurodegenerative disease } \\
\hline Motor neurone disease & GI22 \\
\hline Parkinson's disease & G20 \\
\hline Huntington's disease & GIO \\
\hline Alzheimer's & G300, G30I, G308, G309 \\
\hline HIVIAIDS & B20-B24 \\
\hline \multicolumn{2}{|l|}{ Our refined method } \\
\hline Malignant neoplasm & $\mathrm{C} 00-\mathrm{C} 97$ \\
\hline Heart disease, including cerebrovascular disease & $100-152,160-169$ \\
\hline Renal disease & $N|7, N| 8, N 28,112,113$ \\
\hline Liver disease & K70-K77 \\
\hline Respiratory disease & J06-J $18, J 20-J 22, J 40-J 47 \&$ J96 \\
\hline Neurodegenerative disease & GI0, G20, G35, G122, G903, G231 \\
\hline Alzheimer's, dementia and senility & F0I, F03, G30, R54 \\
\hline HIVIAIDS & B20-B24 \\
\hline
\end{tabular}

ICD- I0: International Statistical Classification of Diseases and Related Health Problems-I0th Revision

Table 3. Number of deaths in England by specified conditions, 2006-2008, comparing numbers derived using Rosenwax's ICD- 10 codes and our refined method.

\begin{tabular}{|c|c|c|c|c|}
\hline Rosenwax method ${ }^{7}$ & $n$ & Our method & $n$ & Difference \\
\hline \multirow[t]{5}{*}{ Neoplasm } & 392,655 & Cancer (breast) & 30,486 & 9144 \\
\hline & & Cancer (colorectal) & 38,789 & \\
\hline & & Cancer (lung) & 83,332 & \\
\hline & & Cancer (other) & 205,135 & \\
\hline & & Cancer (prostate) & 25,769 & \\
\hline \multirow[t]{2}{*}{ Heart failure } & 24,069 & Heart disease (chronic) & 173,012 & 281,117 \\
\hline & & $\begin{array}{l}\text { Cerebrovascular disease } \\
\text { (stroke) }\end{array}$ & 132,174 & \\
\hline Renal failure & 4380 & $\begin{array}{l}\text { Renal disease (chronic renal } \\
\text { failure) }\end{array}$ & 5220 & 840 \\
\hline Liver failure & 2085 & Liver disease & 20,702 & 18,617 \\
\hline \multirow[t]{2}{*}{$\begin{array}{l}\text { Chronic obstructive } \\
\text { pulmonary disease }\end{array}$} & 67,425 & $\begin{array}{l}\text { Respiratory disease (chronic } \\
\text { lung disease) }\end{array}$ & 73,082 & 5719 \\
\hline & & $\begin{array}{l}\text { Respiratory disease } \\
\text { (respiratory failure) }\end{array}$ & 62 & \\
\hline Huntington's disease & 523 & Neurodegenerative disease & 21,047 & 3281 \\
\hline Motor neurone disease & 4760 & & & \\
\hline Parkinson's disease & 12,483 & & & \\
\hline Alzheimer's disease & 15,842 & $\begin{array}{l}\text { Dementia, Alzheimer's, } \\
\text { senility }\end{array}$ & 84,462 & 68,620 \\
\hline HIVIAIDS & 684 & HIVIAIDS & 684 & 0 \\
\hline $\begin{array}{l}\text { Total of deaths from these } \\
\text { conditions }\end{array}$ & $\begin{array}{l}524,906 \\
\text { ( } 37 \% \text { of all } \\
\text { deaths) }\end{array}$ & $\begin{array}{l}\text { Total of deaths from these } \\
\text { conditions }\end{array}$ & $\begin{array}{l}893,956 \\
\text { (63\% of all deaths) }\end{array}$ & 369,050 \\
\hline Total deaths in England & $|, 4| 8,35 \mid$ & Total deaths in England & $|, 4| 8,35 \mid$ & - \\
\hline
\end{tabular}

ICD-I0: International Statistical Classification of Diseases and Related Health Problems-I0th Revision. 
Table 4. Cumulative per cent of deaths from conditions specified in the minimal estimate with hospitalisations, by period of admission to hospital before death.

\begin{tabular}{|c|c|c|c|c|c|}
\hline \multirow[t]{2}{*}{ Underlying cause of death } & \multicolumn{4}{|c|}{ Cumulative per cent admitted to hospital } & \multirow[t]{2}{*}{ All deaths (\%) } \\
\hline & $\begin{array}{l}\text { I week before } \\
\text { death }\end{array}$ & $\begin{array}{l}3 \text { months } \\
\text { before death }\end{array}$ & $\begin{array}{l}6 \text { months } \\
\text { before death }\end{array}$ & $\begin{array}{l}\text { I year before } \\
\text { death }\end{array}$ & \\
\hline Cancer (breast) & 20 & 69 & 76 & 82 & 100 \\
\hline Cancer (colorectal) & 17 & 70 & 79 & 85 & 100 \\
\hline Cancer (lung) & 22 & 75 & 82 & 86 & 100 \\
\hline Cancer (other) & 19 & 77 & 84 & 88 & 100 \\
\hline Cancer (prostate) & 18 & 70 & 79 & 84 & 100 \\
\hline Heart disease (heart failure) & 26 & 72 & 77 & 81 & 100 \\
\hline Heart disease (other heart disease) & 22 & 52 & 58 & 64 & 100 \\
\hline Cerebrovascular disease (stroke) & 26 & 65 & 7I & 76 & 100 \\
\hline Renal disease (acute renal failure) & 49 & 87 & 88 & 89 & 100 \\
\hline Renal disease (chronic renal failure) & 24 & 70 & 77 & 82 & 100 \\
\hline Liver disease & 28 & 74 & 78 & 82 & 100 \\
\hline Respiratory disease (chronic lung disease) & 31 & 7I & 76 & 80 & 100 \\
\hline Respiratory disease (respiratory failure) & 33 & 59 & 66 & 70 & 100 \\
\hline Neurodegenerative disease & 17 & 54 & 63 & 71 & 100 \\
\hline Dementia, Alzheimer's, senility & 8 & 40 & 48 & 56 & 100 \\
\hline HIVIAIDS & 14 & 59 & 66 & 73 & 100 \\
\hline Total & 22 & 64 & 70 & 75 & 100 \\
\hline
\end{tabular}

specific conditions on death certificates, may contribute to this. Using the linked HES/ONS mortality files, we therefore examined the pattern of hospital admissions over the year prior to death for each of the specified palliative carerelevant conditions. Table 4 reports the proportion of deaths with hospitalisation in the year before death, particularly low (56\%) for dementia, Alzheimer's and senility.

In addition, under-recording of renal disease on death certificates is specifically acknowledged; ${ }^{13,19}$ therefore, our lower mid-range estimate includes all those in the minimal or low estimate together with deaths for which Alzheimer's, dementia or senility or renal disease is recorded as a contributory cause. For the upper mid-range estimate, we included all deaths with any mention of any of the specified chronic conditions for the minimal estimate, either as underlying or contributory cause of death in the death certificate.

The maximal estimate follows the Rosenwax definition ${ }^{7}$ and includes all ONS-registered deaths from all causes, except deaths occurring from the following conditions: during pregnancy, childbirth or puerperium (ICD-10 codes O00-O99); originating during the perinatal period (P00P96); resulting from injury, poisoning and other similar causes (S00-T98) and those resulting from external causes (V01-Y98).

Table 5 shows these different approaches, as applied to the national data available in England. The method developed by Higginson used prevalence of different symptoms that overlap; therefore, it is difficult to get a precise number. In Table 5, we have included estimates using pain, breathlessness and depression, although 'pain' could perhaps be regarded as the most useful. The Rosenwax methods provide a wide range, while GómezBatiste is relatively easy to apply. The more refined methods we have developed concur with the estimate from Higginson based on pain, and our intermediate estimates are most consistent with other approaches. Data on deaths of children and young adults were extracted and included (see Table 6, which reports numbers by age), using the causes likely to have required palliative care as described by Cochrane et al. ${ }^{20}$

\section{Discussion}

We have refined methods for deriving population estimates of palliative care need and successfully applied this to a national population. With our more detailed categorisation of palliative care-relevant conditions, we identify a minimum of $63 \%$ of all deaths, which may need palliative care. This is a marked increase from the $37 \%$ of all deaths, which would be identified if the original Rosenwax method was applied, ${ }^{7}$ and is likely to be a more realistic estimate of population need. The methods adopted by Higginson ${ }^{1}$ and Gómez-Batiste et al. ${ }^{8}$ take account (in different ways) of the prevalence of symptoms and/or chronic conditions/care home residence and may be more suited to local or regional estimations of palliative care need if this epidemiological data are available. 
Table 5. Numbers needing palliative care in England, for the period 2006-2008 and annually, estimated and compared using four different methods.

\begin{tabular}{|c|c|c|c|c|c|c|}
\hline & & \multirow[t]{2}{*}{$n(2006-2008)$} & \multirow[t]{2}{*}{$n$ (annually) } & \multirow[t]{2}{*}{$\begin{array}{l}\text { Percentage of all } \\
\text { deaths }\end{array}$} & \multicolumn{2}{|c|}{$\begin{array}{l}\text { Confidence intervals } \\
(95 \%)\end{array}$} \\
\hline & & & & & Lower limit & Upper limit \\
\hline \multirow[t]{3}{*}{ Higginson' } & Pain & 854,936 & 284,979 & 60.28 & 60.20 & 60.36 \\
\hline & Breathlessness & 554,787 & 184,929 & 39.11 & 39.03 & 39.20 \\
\hline & Depression & 432,481 & 144,160 & 30.49 & 30.42 & 30.57 \\
\hline \multirow[t]{2}{*}{ Rosenwax et al. $^{7}$} & Minimal estimate & 524,906 & 174,969 & 37.01 & 36.94 & 37.07 \\
\hline & Maximal estimate & $\mathrm{I}, 370,30 \mathrm{I}$ & 456,767 & 96.61 & 96.58 & 96.64 \\
\hline Gómez-Batiste et al. ${ }^{8}$ & Estimate & $1,063,763$ & 354,588 & $75 \%{ }^{\mathrm{a}}$ & & \\
\hline \multirow{4}{*}{$\begin{array}{l}\text { Murtagh (methods } \\
\text { developed in this article) }\end{array}$} & Minimal estimate & 893,956 & 297,985 & 63.03 & 62.95 & 63.11 \\
\hline & $\begin{array}{l}\text { Intermediate estimate - } \\
\text { lower limit }\end{array}$ & 980,056 & 326,685 & 69.10 & 69.02 & 69.17 \\
\hline & $\begin{array}{l}\text { Intermediate estimate - } \\
\text { upper limit }\end{array}$ & $1,|6|, 201$ & 387,067 & 81.87 & 81.81 & 81.93 \\
\hline & Maximal estimate & $\mathrm{I}, 370,30 \mathrm{I}$ & 456,767 & 96.61 & 96.58 & 96.64 \\
\hline \multicolumn{2}{|l|}{ Total deaths } & $|, 4| 8,35 \mid$ & 472,784 & 100 & & \\
\hline
\end{tabular}

aThe actual numbers are derived from the per cent; therefore, $95 \%$ confidence intervals are not presented.

Table 6. Comparison of low, mid-range and upper estimates, by age as applied to deaths in England, 2006-2008.

\begin{tabular}{|c|c|c|c|c|c|}
\hline Age (years) & Minimal estimate & $\begin{array}{l}\text { Mid-range estimate } \\
\text { (lower limit) }\end{array}$ & $\begin{array}{l}\text { Mid-range estimate } \\
\text { (upper limit) }\end{array}$ & Maximal estimate & Total deaths \\
\hline $0-1$ & 148 & 159 & 639 & 9463 & 10,158 \\
\hline $2-13$ & 660 & 672 & 905 & 2075 & 2546 \\
\hline $14-18$ & 412 & $4 \mid 4$ & 549 & 1380 & 2562 \\
\hline 19-24 & 727 & 745 & 1037 & 2513 & 5339 \\
\hline $25-64$ & $\mid 44,288$ & $|46,6| \mid$ & 172,468 & 203,737 & 224,634 \\
\hline $65+$ & 747,721 & 831,455 & 985,603 & $1,151,133$ & $1,173,112$ \\
\hline Total $(n)$ & 893,956 & 980,056 & $1,161,201$ & $\mathrm{I}, 370,30 \mathrm{I}$ & $|, 4| 8,35 \mid$ \\
\hline
\end{tabular}

Specialist palliative care is provided in a variety of settings, including in dedicated inpatient palliative care beds (mainly provided in hospices but including small numbers of dedicated specialist palliative care wards within hospitals), in the patient's own home or care home (home-based care) or on an advisory basis while receiving acute hospital care from other specialities. Where data about provision of these services are available, our refined method can be further triangulated. The national survey of specialist palliative care services in England reports that in 2010, 46,800 people were admitted to specialist palliative care inpatient beds, 95,600 people receive home-based palliative care per annum and 100,000 people receive specialist palliative care in the hospital setting. ${ }^{21}$ Although the extent to which these groups overlap is unknown, together these numbers indicate that between 100,000 (assuming complete overlap) and 242,400 people (assuming no overlap) receive specialist palliative care in England annually. ${ }^{21}$ This does not include those with less complex needs receiving palliative care from primary and community care teams alone (general palliative care), nor those whose palliative care needs go unrecognized. ${ }^{22,23}$ However, it can provide some context for our estimation of population need. We anticipate that our estimates, ranging from 297,985 (minimal estimate) to $326,685-387,067$ (mid-range) people per annum, should be notably higher than those reported by services as receiving specialist palliative care (i.e. 100,000242,000), and this is in fact the case. Similar service-based data for specialist palliative care may be available in other countries or regions to triangulate in a comparable way.

We recognise that cause of death, while indicative of potential palliative care need, is not a precise indicator. There are a number of reasons for this. First, palliative care needs do not map well to diagnosis. There is widespread recognition that palliative care needs (physical symptoms, psychological distress, family and social support, informational and practical needs) are determined by much more complex and interacting factors than diagnosis alone. ${ }^{23,24}$ However, palliative care was developed and is still largely delivered to those with advanced cancer; ${ }^{21}$ it is extending 
rapidly to those with non-cancer conditions, ${ }^{25-27}$ but diagnosis remains a major consideration in referral for palliative care. Second, cause of death may not always be an accurate reflection of diagnosis. A variety of reasons affect what is recorded on a death certificate, but certain conditions, such as dementia, ${ }^{28}$ Parkinson's disease ${ }^{29}$ and renal disease, ${ }^{13,19}$ are particularly under-recorded. We have attempted to allow for this by including both the contributory cause of death and the underlying cause of death in our mid-range estimates. In the mid-range lower limit, we add the 'contributory' causes for those conditions with particularly poor accuracy at the reporting underlying cause. In our mid-range upper limit, we adopt this approach for all palliative care-relevant conditions. Third, estimating palliative care need through the number of deaths does not reflect the trajectory of those needs prior to death; this may be particularly relevant for children and young people, where the overall numbers of deaths are small (see Table 3 ) but the trajectory of palliative care needs for some conditions may extend over several years. ${ }^{20}$ There is also a distinct difference between palliative care needs in the last few weeks of life (which may largely include generalist palliative care, with some specialist palliative care for the more complex) and palliative care services needed earlier in the illness trajectory, such as management of challenging symptoms or complex psychological needs (which may be more commonly provided by specialist palliative care services). The former is more closely related to a population-based mortality statistics approach, while the latter may depend to a greater extent on overall illness trajectory (and pattern of need over time) as well as the absolute numbers.

Assessing hospital admissions through the linked ONS/ HES dataset allowed us to further consider the mid-range method of Rosenwax et al. ${ }^{7}$ There are advantages and disadvantages to both mid-range methods. The Rosenwax approach moves away from the palliative care-relevant conditions identified for the minimal estimate and concentrates on hospital admission for the same condition that causes death in the year prior to death. This extends the estimate to include any sustained condition, regardless of whether this occurs over a week, month or year prior to death, but has the disadvantage that many countries are now trying to reduce hospital admissions and promote home care - where this has been achieved, adopting this approach may underestimate need and effectively 'penalise' regions with high home death rates. This may have the advantage of incorporating conditions that may need palliative care, but where this has not been widely recognised for that diagnostic group. Our approach retains the focus on those conditions identified by expert consensus as most relevant for palliative care but considers (in so far as is possible at population level) the limitations caused by under-reporting on death certificates. Including both upper and lower limits of this approach enables those providing, commissioning or planning for palliative care services to select the most pertinent approach, according to purpose.

Knowing the numbers in a population needing palliative care is invaluable for service planning and development. Palliative care is known to improve patient and family outcomes. ${ }^{27,30-32}$ Clear information for the public, commissioners, policy-makers and providers on how many people might be expected to need palliative care, nationally or regionally, can inform whether sufficient palliative care services are being commissioned and provided. All three of our refined estimates (minimal, mid-range and maximal) presented in this article can be derived for local and regional populations, using readily available data, thus allowing commissioners to estimate how many people need palliative care in their Clinical Commissioning group area and commission accordingly.

We recommend that this approach could be further refined in future work, to adapt the approach to each setting, and draw on other local data sources, such as those recommended in recent commissioning guidance for England. ${ }^{6}$ These methods can be readily applied in other countries where death registration data, coded using $I C D$ 10 , are available. Some countries may have local (but not national) service-based data on specialist palliative care provision; but local or regional analysis of death registrations in the way we have described can still provide useful estimates of palliative care need, and these can be triangulated against current provision. Population-based estimates of palliative care need also enable new initiatives and funding models to be developed; this work, for instance, has been used to inform the 2011 Palliative Care Funding Review for England. ${ }^{33}$

\section{Acknowledgements}

We thank Rosenwax and colleagues and Gómez-Batiste and colleagues for their original work that helped inform this article.

\section{Declaration of conflicting interests}

The authors declare that there are no conflicts of interest. The views and opinions expressed therein are those of the authors and do not necessarily reflect those of the Review team.

\section{Funding}

This work was partly funded by the independent Palliative Care Funding Review for England.

\section{References}

1. Higginson IJ. Health care needs assessment: palliative and terminal care. In: Stevens A and Raftery J (eds) Health care needs assessment. Oxford: Radcliffe Medical Press, 1997, pp. 1-28.

2. Culyer AJ. Need: the idea won't do - but we still need it. Soc Sci Med 1995; 40(6): 727-730.

3. Bradshaw J. A taxonomy of social need. New Soc 1972; 30: 640-643. 
4. Payne S and Radbruch L. White paper on standards and norms for hospice and palliative care in Europe: part 1. Eur $J$ Palliat Care 2009; 16(6): 278-289.

5. National Institute for Clinical E. Improving supportive and palliative care for adults with cancer. London: National Institute for Clinical Excellence, 2004.

6. Association for Palliative Medicine, Group CNiPCR, Marie Curie Cancer Care, National Council for Palliative Care, Palliative Care Section of the Royal Society of Medicine. Commissioning guidance for specialist palliative care. London: Association for Palliative Medicine of Great Britain and Ireland, 2012.

7. Rosenwax LK, McNamara B, Blackmore AM, et al. Estimating the size of a potential palliative care population. Palliat Med 2005; 19(7): 556-562.

8. Gómez-Batiste X, Martinez-Munoz M, Blay C, et al. Identifying needs and improving palliative care of chronically ill patients: a community-oriented, population-based, public-health approach. Curr Opin Support Palliat Care 2012; 6(3): 371-378.

9. Office for National Statistics T. Causes of death 2006-2008. Available at: http://www.statistics.gov.uk/hub/health-socialcare/health-of-the-population/causes-of-death/ (2010).

10. World Health Organization. International Statistical Classification of Diseases and Related Health Problems, 10th Revision.World Health Organization. Available at: http:// www.who.int/classifications/icd/en/ (2010, accessed 10 October 2012).

11. Authority UKS. Office for National Statistics 2008, www.statistics.gov.uk

12. A guide to linked HES-ONS mortality data. Hospital Episode Statistics. Available at: http://www.hesonline.nhs.uk (2011, accessed 20 June 2012).

13. Li SQ, Cass A and Cunningham J. Cause of death in patients with end-stage renal disease: assessing concordance of death certificates with registry reports. Aust N Z J Public Health 2003; 27(4): 419-424.

14. Harris S, Ho D and Verne J. Deaths from Alzheimer's disease, dementia and senility in England. London: National End of Life Care Intelligence Network, 2010.

15. Maxwell R, Ho D, Hounsome L, et al. Deaths from neurodegenerative diseases in England, 2001-2008 (rev. November 2010). London: National End of Life Care Intelligence Network, 2010.

16. Ho D, Harris S and Verne J. Deaths from renal diseases in England, 2001-2008. London: National End of Life Care Intelligence Network, 2010.

17. Ruth K, Pring A and Verne J. Variations in place of death in England: inequalities or appropriate consequences of age, gender, and cause of death? London: National End of Life Care Intelligence Network, 2010.

18. Ruth K and Verne J. Deaths in older adults in England. London: National End of Life Care Intelligence Network, 2010.
19. Perneger TV, Klaq MJ and Whelton PK. Cause of death in patients with end stage renal disease: death certificates vs registry reports. Am J Public Health 1993; 83(12): 1735-1738.

20. Cochrane H, Liyange S and Nantambi R. Palliative care statistics for children and young adults. London: Department of Health, 2007.

21. National Council for Palliative C. National survey of patient activity data for specialist palliative care services: MDS full report for the year 2008-2009. London: National Council for Palliative Care, 2010.

22. To TH, Greene AG, Agar MR, et al. A point prevalence survey of hospital inpatients to define the proportion with palliation as the primary goal of care and the need for specialist palliative care. Intern Med J 2011; 41(5): 430-433.

23. McIlfatrick S. Assessing palliative care needs: views of patients, informal carers and healthcare professionals. $J A d v$ Nurs 2007; 57(1): 77-86.

24. Higginson IJ and Addington-Hall JM. Palliative care needs to be provided on basis of need rather than diagnosis. BMJ 1999; 318(7176): 123.

25. Field D and Addington-Hall J. Extending specialist palliative care to all? Soc Sci Med 1999; 48(9): 1271-1280.

26. Addington-Hall J. Reaching out: specialist palliative care for adults with non-malignant diseases. London: National Council for Specialist Palliative Care and Hospices, 1998.

27. Gomes Barbara AUHI. Effectiveness and cost-effectiveness of home palliative care services for adults with advanced illness and their caregivers (Protocols). Cochrane Database Syst Rev 2009; (2).

28. Martyn CN and Pippard EC. Usefulness of mortality data in determining the geography and time trends of dementia. $J$ Epidemiol Community Health 1988; 42(2): 134-137.

29. Phillips NJ, Reay J and Martyn CN. Validity of mortality data for Parkinson's disease. J Epidemiol Community Health 1999; 53(9): 587-588.

30. Goodwin DM, Higginson IJ, Myers K, et al. Effectiveness of palliative day care in improving pain, symptom control, and quality of life. J Pain Symptom Manage 2003; 25(3): 202-212.

31. Higginson IJ, Finlay IG, Goodwin DM, et al. Is there evidence that palliative care teams alter end-of-life experiences of patients and their caregivers? J Pain Symptom Manage 2003; 25(2): 150-168.

32. Higginson IJ, McCrone P, Hart SR, et al. Is short-term palliative care cost-effective in multiple sclerosis? A randomized phase II trial. J Pain Symptom Manage 2009; 38(6): 816-826.

33. Hughes-Hallet T, Craft A, Davies C, et al.Palliative care funding review: funding the right care and support for everyone, 2011. Available at: https://www.gov.uk/government/ publications/independent-palliative-care-funding-review (accessed 04 May 2013). 